\title{
Stereotactic radiosurgery for brain metastases: analysis of outcome and risk of brain radionecrosis
}

\author{
Giuseppe Minniti ${ }^{1}{ }^{2 *}$, Enrico Clarke ${ }^{1}$, Gaetano Lanzetta ${ }^{2}$, Mattia Falchetto Osti ${ }^{1}$, Guido Trasimeni ${ }^{3}$, \\ Alessandro Bozzao ${ }^{3}$, Andrea Romano ${ }^{3}$ and Riccardo Maurizi Enrici ${ }^{1}$
}

\begin{abstract}
Purpose: to investigate the factors affecting survival and toxicity in patients treated with stereotactic radiosurgery (SRS), with special attention to volumes of brain receiving a specific dose (V10 - V16 Gy) as predictors for brain radionecrosis.

Patients and Methods: Two hundred six consecutive patients with 310 cerebral metastases less than $3.5 \mathrm{~cm}$ were treated with SRS as primary treatment and followed prospectively at University of Rome La Sapienza Sant'Andrea Hospital. Overall survival, brain control, and local control were estimated using the Kaplan-Meier method calculated from the time of SRS. Univariate and multivariate analysis using a Cox proportional hazards regression model were performed to determine the predictive value of prognostic factors for treatment outcome and SRS-related complications.

Results: Median overall survival and brain control were 14.1 months and 10 months, respectively. The 1-year and 2 -year survival rates were $58 \%$ and $24 \%$, and respective brain control were $43 \%$ and $22 \%$. Sixteen patients recurred locally after SRS, with 1-year and 2-year local control rates of 92\% and 84\%, respectively. On multivariate analysis, stable extracranial disease and KPS $>70$ were associated with the most significant survival benefit. Neurological complications were recorded in 27 (13\%) patients. Severe neurological complications (RTOG Grade 3 and 4) occurred in $5.8 \%$ of patients. Brain radionecrosis occurred in $24 \%$ of treated lesions, being symptomatic in $10 \%$ and asymptomatic in 14\%. On multivariate analysis, V10 through V16 Gy were independent risk factors for radionecrosis, with V10 Gy and V12 Gy being the most predictive $(p=0.0001)$. For V10 Gy $>12.6 \mathrm{~cm}^{3}$ and $\mathrm{V} 12 \mathrm{~Gy}>10.9 \mathrm{~cm}^{3}$ the risk of radionecrosis was $47 \%$.
\end{abstract}

Conclusions: SRS alone represents a feasible option as initial treatment for patients with brain metastases, however a significant subset of patients may develop neurological complications. Lesions with V12 Gy $>8.5 \mathrm{~cm}^{3}$ carries a risk of radionecrosis $>10 \%$ and should be considered for hypofractionated stereotactic radiotherapy especially when located in/near eloquent areas.

Keywords: brain metastases stereotactic radiosurgery, survival, radiation-induced complications, brain necrosis

\section{Introduction}

Stereotactic radiosurgery (SRS) has become an increasingly treatment option in the initial management of patients with brain metastases. Its efficacy when used alone or in combination with whole brain radiationtherapy (WBRT) has been demonstrated in several

\footnotetext{
* Correspondence: gminniti@ospedalesantandrea.it

'Department of Radiation Oncology, Sant' Andrea Hospital, University "La Sapienza", Rome, Italy

Full list of author information is available at the end of the article
}

randomized trials and multi-institutional studies [1-8]. SRS plus WBRT is associated with better local tumor control and functional autonomy for patients with brain metastases when compared to WBRT alone, and with significant longer survival in patients with a single metastasis [3]. Recently, two large randomized studies have shown similar survival benefits and functional independence between patients with 1-3 brain metastases treated with SRS alone and SRS plus WBRT $[7,8]$.

\section{Ciomed Central}

(c) 2011 Minniti et al; licensee BioMed Central Ltd. This is an Open Access article distributed under the terms of the Creative Commons Attribution License (http://creativecommons.org/licenses/by/2.0), which permits unrestricted use, distribution, and reproduction in any medium, provided the original work is properly cited. 
The reported survival of 7-14 months after SRS is roughly equivalent to that reported after surgical resection [9]. Although surgery is usually indicated in patients with lesions causing significant mass effect and for large lesions $>3 \mathrm{~cm}$ in locations amenable to resection, in current clinical practice SRS is frequently employed as less invasive and more cost-effective treatment option than resection.

A variable rate of neurological complications of $2-14 \%$ has been reported after SRS [7,8,10-17]; however, a higher rate has been shown in some studies [1,18-20] suggesting that patients may have side-effects after SRS more often than reported. The most common complication of SRS is represented by the development of brain radionecrosis that may occur in up to $50 \%$ of treated lesions [21-26]. Factors related to the development of radionecrosis after SRS include dose, treated volume, and volume of the brain receiving a specific dose [22,23,25-28]

In the present study we have reviewed our experience with SRS in patients with brain metastases treated with SRS alone as primary treatment. Related factors associated with the clinical outcome and the development of treatment-induced complications have been evaluated.

\section{Patients and Methods}

Between September 2006 and January 2010, 206 consecutive patients aged 18 years or older with 1-3 cerebral metastases less than $3.5 \mathrm{~cm}$ on contrast-enhanced magnetic resonance imaging (MRI), and derived from an histologically confirmed systemic cancer, were treated with SRS as primary treatment and followed prospectively at University of Rome La Sapienza Sant'Andrea Hospital. Patients who had received previous surgical resection or WBRT, or receiving adjuvant WBRT following SRS were excluded from the study.

All metastatic tumors were treated with LINAC-based SRS. The BrainLAB frameless stereotactic system, in conjunction with the BrainScan treatment planning system (Version 5.31) has been used for stereotactic treatment. The target volume was identified on the basis of the fused CT and magnetic resonance image (MRI) scans. Radiosurgical dose was 20 Gy for metastases with a volume $\leq 4.3 \mathrm{~cm}^{3}$ (corresponding to a sphere of $2 \mathrm{~cm}$ in diameter), $18 \mathrm{~Gy}$ for metastases with a volume of 4.3$14.1 \mathrm{~cm}^{3}$, and 15-16 Gy for metastases with a volume > $14.1 \mathrm{~cm}^{3}$ or located in the brainstem. The gross tumor volume (GTV) was delineated as a contrast-enhancing tumor demonstrated on MRI scans. The planning target volume (PTV) was generated by the geometric expansion of GTV plus 1-2 $\mathrm{mm}$. Doses were prescribed to the $80-90 \%$ isodose line normalized to the maximum dose. Treatment volumes were achieved with 6-10 noncoplanar dynamic arcs by using a 6-MV LINAC. All patients underwent a second CT (verification CT) scan before the start of treatment in the CT-room and immediately transferred to the treatment room in a wheel chair. Planning and verification CT scans were fused employing a fusion algorithm included in the BrainLab planning system. The new coordinates of the isocenter were recorded and the isocenter shift between verification and planning CT calculated as previously reported [29]. This whole procedure takes less than 10 minutes. The mask was refitted or the treatment replanned if the isocenter shift was $>1.0 \mathrm{~mm}$. Patients with multiple metastases were treated in 2 or 3 following days in outpatient clinic.

Patients were examined clinically one month after radiosurgical treatment and then every 2 months. MRI was made every 2 months in the first year after the treatment, and then every 3 months or as appropriate according to the neurological conditions. The size of treated lesions was measured in three dimensions. Complete and partial responses were defined as total radiographic disappearance of lesion or decrease in tumor volume $>50 \%$. Local progression was defined as radiographic increase in the size of metastatic lesion. For all patients who died, the cause of death (intracranial versus extracranial progression) was determined by clinical/ neurological evaluation and brain/systemic radiologic studies. Patients were considered to have died as result of a neurological death if they had evidence of progressive intracranial disease consisting of expanding intracranial masses, CNS hemorrhage, progressive neurologic symptoms, meningeal carcinomatosis, or hydrocephalus resulting in herniation.

At each visit, neurological status and the severity of complications were rated according to RTOG CNS toxicity criteria. Severe complications were considered to have an RTOG Grade $\geq 3$ ). Adverse neurological events were considered consequence of SRS treatment if they were associated or not to radiological abnormalities suggestive of brain radionecrosis in absence of progressive disease. Radionecrosis was assessed subjectively using anatomic and dynamic susceptibility-weighted contrastenhanced (DSC) perfusion MRI. The following criteria have been considered as suggestive of radionecrosis: 1 ) increased $\mathrm{T} 1$ contrast enhancement located in the irradiated area with central hypointensity and increased peripheral edema; 2) substantial regression or stability (for at least 4 months) of enhancing areas on serial followup MRI scans without additional treatment; 3) a clear absence of perfusion (black hole), in the absence of any nodular highly vascularized area within the contrastenhanced lesion at perfusion MRI. Enhancing lesion that progressively increased in size on serial MR imaging during a minimum follow-up period of 4 months was scored as recurrent metastatic tumor. All diagnoses 
were confirmed retrospectively by the same experienced neuroradiological team (AB, AR, GT). Radionecrosis was recorded as clinically symptomatic when associated with neurological deterioration, whereas was recorded as asymptomatic in patients who remained neurologically stable.

\section{MRI protocol}

All MRI scans were obtained with a 1.5-T MRI scanner (Siemens Sonata, Siemens Medical Systems, Erlangen, Germany). After a localizing sagittal T1-weighted image, non-enhanced axial T1-weighted spin echo (TR/TE, 600/12 ms) and axial T2-weighted (TR/TE 3,680/85) images were obtained. Post-contrast axial and sagittal (multiplanar reconstruction) T1-weighted imaging was performed after the acquisition of the DSC MRI data. DSC MRI scans were acquired using a T2-weighted (TR/TE/flip angle:1.490/40/90 ) EPI sequence. A dynamic image series of 50 measurements performed on 14 axial sections with slice thickness $5 \mathrm{~mm}$ and interslice gap $1.5 \mathrm{~mm}$ resulted in a total scan time of 1.20 min, with a field of view of $230-230 \mathrm{~mm}$, matrix 128128 and an image acquisition matrix of $128 \times 128$, signal bandwidth 1502 . A dose $0.1 \mathrm{mmol} / \mathrm{kg}$ bolus injection of gadolinium contrast (Magnevist; Shering Diagnostics, Berlin, Germany) delivered at the rate of $5 \mathrm{ml} / \mathrm{s}$ was used. The post-processing of the DSC MRI data were performed on a Leonardo VD10B Syngo OEM installation (Siemens AG).

\section{Data analysis}

Overall survival, brain control, and local control (control of irradiated lesions) were estimated using the KaplanMeier method calculated from the time of SRS. For univariate analysis, the log-rank test was used for categorical variables, and the Cox proportional hazards model was used for continuous variables. The following factors for outcome were tested: age ( $<65 v s \geq 65$ years), pretreatment KPS score $(\leq 70 v s>70)$, number of brain metastases $(1 v s>1)$, recursive partitioning analysis (RPA) class (I vs II vs III), histology (lung vs breast vs melanoma $v s$ others), and extracranial disease (stable $v s$ active). Radionecrosis changes were assessed per tumor and event-free survival time using the Kaplan-Meier method. Univariate analysis was performed to identify risk factors for the presence of radionecrosis by using the following patient and tumor determinants: sex, age, histology, KPS score, tumor volume, SRS dose, volume receiving a specific dose of 10,12,14,16 and 18 Gy (V10 Gy-V18 Gy), site of tumor, conformality index [30], and homogeneity index. Prognostic factors for treatment outcome and SRS-related complications found significant $(\mathrm{P}<0.05)$ were included in a multivariate outcome with analysis performed using a Cox proportional hazards regression model. In order to compare the own results with previously published risk prediction models, we have analyzed the correlation between V10 and V12 Gy and the increased risk of brain necrosis. Volumes were divided in intervals determined by quantiles and the risk of necrosis calculated in each interval. A probability value $<0.05$ was considered statistically significant.

\section{Results}

\section{Patients and tumor characteristics}

Two hundred six patients (109 males and 97 females) with 310 metastases who underwent SRS between September 2006 and January 2010 and who met the previously described inclusion criteria were analyzed. Tumor characteristics are listed in Table 1. One hundred twenty-six patients (61\%) were treated for 1 metastasis, 56 (27\%) for 2 metastases, and 24 patients (12\%) for 3 metastases. The median age at the time of SRS was 62 years (range 26-81). The most common

Table 1 Summary of tumor characteristics and treatment parameters

\begin{tabular}{|c|c|}
\hline Parameter & $\mathrm{No}(\%)$ \\
\hline number of patients & 206 \\
\hline median age & 62 \\
\hline $\operatorname{sex}(F / M)$ & $99 / 107$ \\
\hline \multicolumn{2}{|c|}{ no of lesions per patient } \\
\hline 1 lesion & $126(61 \%)$ \\
\hline 2 lesions & $56(27 \%)$ \\
\hline 3 lesions & $24(12 \%)$ \\
\hline \multicolumn{2}{|l|}{ histology } \\
\hline lung & 106 (51\%) \\
\hline breast & $38(18 \%)$ \\
\hline melanoma & $34(17 \%)$ \\
\hline others & $28(14 \%)$ \\
\hline \multicolumn{2}{|l|}{ tumor location } \\
\hline frontal & $68(22 \%)$ \\
\hline parietal & $78(25 \%)$ \\
\hline temporal & $62(20 \%)$ \\
\hline cerebellar & 43 (14\%) \\
\hline occipital & $45(15 \%)$ \\
\hline brainstem & $14(4 \%)$ \\
\hline \multicolumn{2}{|c|}{ radiosurgical dose (Gy) } \\
\hline 20 & 118 (38\%) \\
\hline 18 & 120 39\%) \\
\hline $15-16$ & $72(23 \%)$ \\
\hline \multicolumn{2}{|l|}{ treated volume $\left(\mathrm{cm}^{3}\right)$} \\
\hline median & 1.88 \\
\hline range & 0.03-18.1 \\
\hline \multicolumn{2}{|l|}{ treated volume $\left(\mathrm{cm}^{3}\right)$} \\
\hline median & 2.81 \\
\hline range & $0.2-23.7$ \\
\hline
\end{tabular}


histologies were lung, breast, and melanomas. The most common location was parietal lobe followed by frontal and temporal lobe. According to RTOG recursive partitioning analysis (RPA) classes for brain metastases, 49 (24\%) patients were in RPA Class I, 133 (65\%) patients in RPA Class II, and 24 (11\%) patients in RPA Class III. One hundred and fifty-six patients received chemotherapy before treatment or during the subsequent followup. Data were reported to September 2010. At this time 91 patients were alive.

The median GTV was $1.88 \mathrm{~cm}^{3}$ (range $0.03-18.1 \mathrm{~cm}^{3}$ ), and the median PTV was $2.81 \mathrm{~cm}^{3}$ (range $0.2-23.7 \mathrm{~cm}^{3}$ ). Mean prescribed dose was 18 Gy (range 15-20 Gy) at a median isodose of $87 \%$ (range $84-91$ ). The average homogeneity index was 1.1 (range 1-1.3), and the median conformality index was 1.6 (range 1.1-2.7).

\section{Overall survival and brain control}

At a median clinical follow-up of 9.4 months (range 242 months) median survival and brain control were 14.1 months and 10 months, respectively (Figure 1). The 1year and 2-year survival rates were $58 \%$ and $24 \%$, and respective brain control rates were $43 \%$ and $22 \%$. Seventy-nine percent of patients succumbed to their extracranial disease and $21 \%$ of patients died of progressive intracranial disease. Intracranial tumor progression at either distant or local sites in the brain was observed in 74 patients. Sixty-three patients had new brain metastases at distant sites. The 6-month and 12-month actuarial rates of developing new brain metastases were $26 \%$ and $50 \%$, respectively. Sixteen patients recurred locally after SRS. The 1-year and 2-year local control rates were $92 \%$ and $84 \%$, respectively. Salvage WBRT was applied in 47 patients and salvage SRS in 21 patients. Ninety-two (30\%) metastases had a complete response, 106 (34\%) had a partial response, and 112 (36\%) remained stable. A clinical neurological

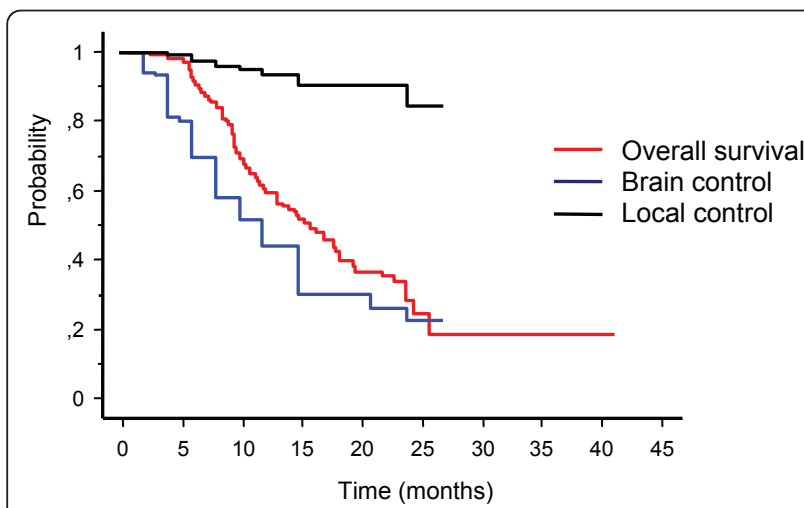

Figure 1 Kaplan-Meier analysis of overall survival, brain control, and local control improvement of pre-RT existing symptoms was recorded in 26 out of 77 patients (34\%) during the follow-up.

Analysis of prognostic factors showed that extracranial disease, KPS, number of metastases, and RPA class were significant predictive factors for survival (Table 2). Histopathological type, age, and sex were not shown to be a significant factor. On multivariate analysis stable extracranial disease and KPS > 70 were associated with the most significant survival benefit. RPA class was not included in the multivariate analysis because it is not independent of age, KPS and extracranial disease status. Univariate analysis showed that control of extracranial disease $(\mathrm{P}=0.01), \mathrm{KPS}>70(\mathrm{P}=0.03)$, and number of metastases $(1 \mathrm{vs}>1, \mathrm{P}=0.01)$ were significant predictive factors for brain control; however, only extracranial disease $(P=0.001)$ and number of metastases $(P=0.03)$ were independent predictors on multivariate analysis. No significant prognostic factors were associated with local control.

\section{Analysis of complications}

Brain radionecrosis, as suggested by MR imaging or confirmed by histology $(\mathrm{n}=12)$, was the most important complication occurring in 75 (24\%) out of 310 treated lesions. Radionecrosis was symptomatic in 31 (10\%) and asymptomatic in $44(14 \%)$ of the treated lesions. Median time to symptomatic and asymptomatic necrosis were 11 months (range 2-32 months) and 10 months (range 2-30 months), respectively. Neurological deficits associated with radionecrosis including seizure, motor deficits, cognitive deficits, and speech deficits are shown in Table 3. Seizures occurred in 3 patients without evidence of any radiological change suggestive of radionecrosis. Overall, neurological complications were recorded in $28(13.5 \%)$ patients, being severe (RTOG Grade 3 and 4 ) in 12 (5.8\%) patients and requiring surgery or medical treatment. Steroid dependency occurred in 34 patients, with 16 patients who received high-dose dexamethasone for more than 4 months. Other complications were represented by headache, hydrocephalus, hemorrhage in $5 \%, 2 \%$, and $2 \%$, respectively. Overall, neurological and nonneurological complications occurred in $23 \%$ of patients.

Univariate analysis showed that KPS, tumor volume, parietal location, and V10 through V16 Gy were significant variables for either symptomatic or asymptomatic brain necrosis (Table 4). The results of the Cox regression analysis showed that V10 Gy and V12 Gy were the most predictive independent risk factors for radionecrosis $(p=0.0001)$. The correlation was more significant for symptomatic than asymptomatic brain necrosis. In a subsequent analysis we have evaluated the incidence of events according to the V10 and V12 Gy quarpercentiles 
Table 2 Univariate and multivariate survival analysis

\begin{tabular}{|c|c|c|c|c|c|}
\hline \multirow[t]{2}{*}{ Variable } & \multirow[t]{2}{*}{ No. of patients } & \multirow[t]{2}{*}{ Survival time Median months } & \multirow{2}{*}{$\begin{array}{c}\text { univariate analysis } \\
\mathrm{P} \text { value }\end{array}$} & \multicolumn{2}{|c|}{ Multivariate analysis } \\
\hline & & & & Hazard ratio $(95 \% \mathrm{Cl})$ & $P$ value \\
\hline Sex & & & 0.1 & & \\
\hline Male & 109 & 13.5 & & & \\
\hline Female & 97 & 14.7 & & & \\
\hline Age (years) & & & 0.1 & & \\
\hline$<65$ & 122 & 14.6 & & & \\
\hline$\geq 65$ & 84 & 13.3 & & & \\
\hline KPS & & & $<0.0001$ & $2.2(1.4-3.4)$ & 0.007 \\
\hline$\leq 70$ & 95 & 10.1 & & & \\
\hline$>70$ & 111 & 16.1 & & & \\
\hline No of brain metastases & & & 0.03 & $1.5(1-2.2)$ & 0.1 \\
\hline 1 & 126 & 14.7 & & & \\
\hline $2-3$ & 80 & 13.1 & & & \\
\hline Primary tumor & & & 0.2 & & \\
\hline Lung cancer & 106 & 13.9 & & & \\
\hline Breast cancer & 38 & 18.2 & & & \\
\hline Melanoma & 34 & 12.7 & & & \\
\hline Others & 28 & 13.1 & & & \\
\hline Extracranial disease & & & $<0.0001$ & $3.1(1.8-5.0)$ & $<0.001$ \\
\hline stable & 90 & 17.2 & & & \\
\hline active & 116 & 9.8 & & & \\
\hline RPA Class & & & $<0.0001$ & & \\
\hline Class 1 & 49 & 19.2 & & & \\
\hline Class II & 133 & 11.3 & & & \\
\hline Class III & 24 & 7.3 & & & \\
\hline
\end{tabular}

distribution. At a median follow-up of 9.4 months V10 Gy radionecrosis rates were $2.6 \%$ for volumes $<4.5 \mathrm{~cm}^{3}$ $\left(1^{\text {st }}\right.$ quartile, Q1), $11 \%$ for volumes of $4.5-7.7 \mathrm{~cm}^{3}\left(2^{\text {nd }}\right.$ quartile, Q2), $24 \%$ for volumes of $7.8-12.6 \mathrm{~cm}^{3}\left(3^{\text {rd }}\right.$ quartile, Q3), and $47 \%$ for volumes $>12.6 \mathrm{~cm}^{3}\left(4^{\text {th }}\right.$ quartile, Q4). The V12 Gy radionecrosis rates were the same for volumes $<3.3 \mathrm{~cm}^{3}$ (Q1), 3.3-5.9 $\mathrm{cm}^{3}$ (Q2), 6.0-10.9

Table 3 Incidence of complications associated with SRS among 310 metastases

\begin{tabular}{ll}
\hline Type of complication* & No/Total (\%) \\
\hline seizure & $16(5.2)$ \\
motor deficits & $9(2.9)$ \\
sensor deficits & $4(1.3)$ \\
cognitive deficits & $3(1.0)$ \\
speech deficits & $4(1.3)$ \\
visual deficits & $2(0.6)$ \\
ataxia & $5(1.6)$ \\
headache & $15(5)$ \\
nausea & $3(1.0)$ \\
hemorrhage & $5(1.6)$ \\
Cushing syndrome & $7(2.3)$ \\
\hline
\end{tabular}

* Twelve patients had multiple neurological deficits $\mathrm{cm}^{3}$ (Q3), and $>10.9 \mathrm{~cm}^{3}$ (Q4). For V10 Gy $>19.1 \mathrm{~cm}^{3}$ and V12 Gy $>15.4 \mathrm{~cm}^{3}$ corresponding to the $90^{\text {th }}$ percentile the risk of radionecrosis was $62 \%$. The actuarial risk at 1 year for the development of brain radionecrosis was $0 \%$ in Q1, $16 \%$ in Q2, 24\% in Q3, and $51 \%$ for $\mathrm{V} 12$ Gy (Figure 2).

\section{Salvage treatment for intracranial/local progression}

Forty-seven patients received WBRT and 21 patients received further SRS for intracranial progression. Patient receiving WBRT were subsequently excluded from the analysis. Among these patients, the median time to progression was 6 months (range 2-32 months). Median survival after WBRT was 6.7 months. Local progression was treated with resection in 8 patients and WBRT or SRS in 6 patients. Histopathological evaluation of surgically treated lesions showed tumor progression in all patients.

\section{Discussion}

In the present study we have evaluated the clinical outcome and the risk of treatment-related complications in 206 patients treated with SRS as initial treatment for 1-3 brain metastases. Median overall survival and brain 
Table 4 Univariate and multivariate analysis of radiationinduced brain necrosis

\begin{tabular}{lcc}
\hline Variables & Univariate analysis & Multivariate analysis \\
\hline Age & 0.2 & \\
Gender & 0.3 & 0.1 \\
KPS & 0.04 & 0.02 \\
Tumor volume & $<0.0001$ & \\
Dose & 0.09 & 0.2 \\
Conformality index & 0.04 & \\
Homogeneity index & 0.1 & \\
lung histology & 0.1 & \\
Melanoma histology & 0.3 & \\
Breast histology & 0,2 & \\
frontal location & 0.2 & \\
parietal location & 0.03 & \\
temporal location & 0.3 & \\
cerebellar location & 0.2 & \\
occipital location & 0.3 & $0.001^{*}$ \\
brainstem location & 0.9 & $0.001^{* *}$ \\
V10 Gy & $<0.0001$ & $0.005^{\circ}$ \\
V12 Gy & $<0.0001$ & $0.009^{\circ 0}$ \\
V14 Gy & $<0.0001$ & $0.05 \wedge$ \\
V16 Gy & 0.0001 & \\
V18 Gy & 0.001 & \\
\hline
\end{tabular}

*0.003 for symptomatic and 0.04 for asymptomatic brain necrosis ${ }^{*} 0.003$ for symptomatic and 0.04 for asymptomatic brain necrosis ${ }^{\circ} 0.01$ for symptomatic and 0.1 for asymptomatic brain necrosis ${ }^{\circ} 0.02$ for symptomatic and 0.3 for asymptomatic brain necrosis $\wedge 0.03$ for symptomatic and 0.5 for asymptomatic brain necrosis

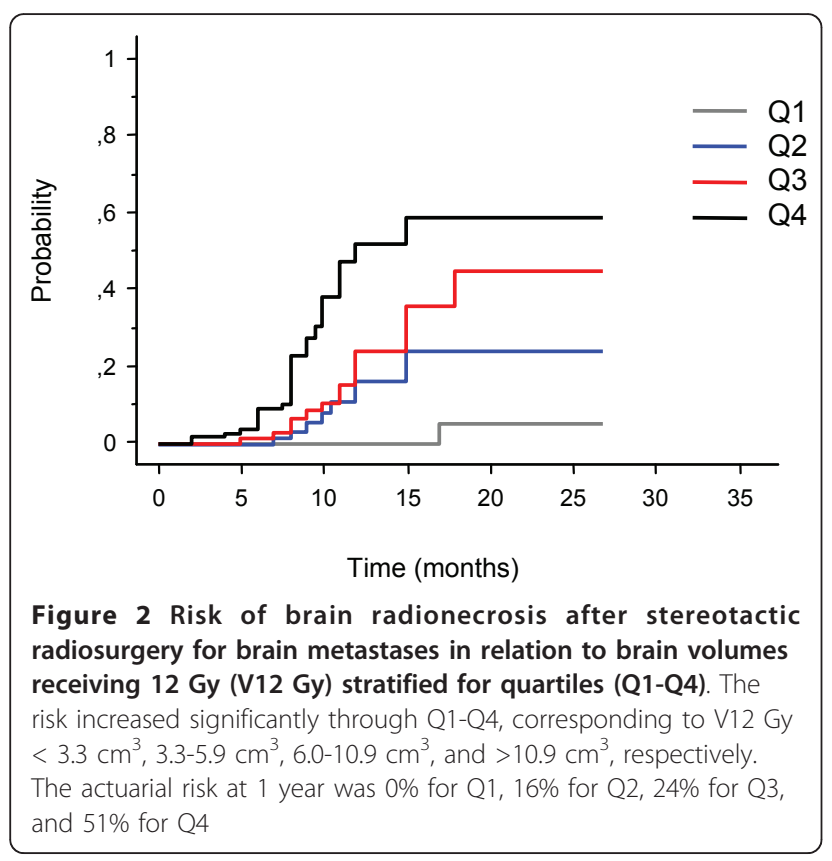

control were 14.1 months and 10 months, respectively. The 1-year and 2-year survival rates were $58 \%$ and $24 \%$, and respective brain control rates were $43 \%$ and $22 \%$. Sixteen patients recurred locally after SRS with 1-year and 2 -year local control of $92 \%$ and $84 \%$, respectively. The reported results are in accordance with previous series of SRS for brain metastases that report a median survival ranging from 7 to14 months [1-8].

Surgery, WBRT, and SRS alone or in combination have been employed as treatment option for patients with either single or multiple brain metastases, although their optimal treatment is still an issue that remains open for debate. Survival advantages with the use of SRS alone or in conjunction with WBRT have been reported by several randomized trials $[2,5,7,8]$. In a series of 132 patients with 1-4 brain metastases randomly assigned to receive WBRT plus SRS or SRS alone Aoyama et al [7] reported no significant difference in survival (8 months versus 7.5 months) and 1-year local control (72.5\% versus $88.7 \%)$. Although SRS alone was associated with increased intracranial progression as compared with WBRT plus SRS, no differences in the frequency of neurologic deaths and preservation of neurologic function were observed. Similarly, the recent EORTC 22952-26001 study on the adjuvant WBRT versus observation after SRS or surgical resection of 1-3 cerebral metastases showed that adjuvant WBRT was able to reduce the frequency of intracranial progression but failed to improve the median survival [8]. Few studies have compared SRS with or without WBRT versus resection plus WBRT, with the majority of them reporting no differences in survival and neurological deaths between groups [31-35]. In a retrospective analysis of 206 patients with one or two metastases, Rades et al [35] reported a similar outcome in patients treated with WBRT plus SRS or surgery plus WBRT and boost. The 1 -year survival and brain control rates were $65 \%$ and $70 \%$ after WBRT plus SRS, and 63\% and 78\% after surgery plus WBRT and boost, respectively. Based on the present results and published data, SRS alone as initial treatment strategy in patients with either single or multiple metastases is a feasible therapeutic option associated with high local control and survival benefits, although the superiority of SRS versus other treatment options in terms of improved survival remains to be demonstrated. Certainly, the high 1-year brain tumor recurrence rates of about 50\% after SRS alone clearly indicates that a frequent monitoring of intracranial disease is mandatory for such patients.

On multivariate analysis, KPS $>70$ and stable extracranial disease were significantly associated with longer survival. Number of metastases did not emerge as significant variable associated with the outcome similarly 
to some recent $[5,6,17]$ and differently from earlier published series $[12,36]$. The high local control after SRS and the improved control of extracranial disease reported with the combination of cytotoxic and targeted agents [37-41] may, at least in part, explain these results. Similarly, older age did not have a negative impact on survival, suggesting that SRS is a feasible and safe approach also in this subgroup of patients $[42,43]$.

Brain necrosis represents the most important late toxicity reported after SRS, leading to neurological complications in $2-32 \%$ of patients [1-10,18-20]. At doses of 16-22 Gy usually employed for the radiosurgical treatment of brain metastases, radionecrosis has been reported in up to $50 \%$ of treated lesions, with radiation dose, tumor volume and location of the lesion being the most important predictive variables [22-26]. In our study, radionecrosis occurred in $24 \%$ of treated lesions with SRS, leading to severe neurological complications (RTOG Grade $\geq 3$ ) in $5.8 \%$ of patients. Other adverse events included headache, iatrogenic Cushing syndrome, and more rarely conditions as haemorrhage and hydrocephalus. The present results confirm that SRS is associated with a relatively high rate of treatment-related complications as reported by some authors, although with an acceptable incidence of severe neurological deficits [18-21].

Analysis of risk factors for brain necrosis showed that V10 Gy and V12 Gy were the most important independent predictors of both symptomatic and asymptomatic radionecrosis. At a median follow-up of 9.4 months the actuarial risk at 1 year for the development brain radionecrosis increased significantly through Q1-Q4, being 0\% in Q1, 16\% in Q2, 24\% in $\mathrm{Q} 3$, and $51 \%$ in Q4. Our data are consistent with previous studies that have shown a significant correlation between volume receiving a dose of 10 or 12 Gy and the development of radionecrosis in patients treated with SRS for brain metastases and other intracranial tumors $[21,22,25,26]$. Blonigen et al [26] in a series of 63 patients with a total of 173 brain metastases treated with SRS have reported a significant radionecrosis risk up to $68.8 \%$ for V10 Gy $>14.5 \mathrm{~cm}^{3}$ and V12 Gy $>10.8$ $\mathrm{cm}^{3}$, respectively. In contrast, no cases of radionecrosis were found for V10 Gy $<0.68 \mathrm{~cm}^{3}$ and V12 Gy $<0.5$ $\mathrm{cm}^{3}$. In a retrospective analysis of 198 intracranial tumors treated with Gamma Knife SRS, Korytko et al [25] confirmed the correlation between the V12 Gy and the risk of symptomatic radionecrosis. The risk was $55.3 \%$ for V12 Gy $>10 \mathrm{~cm}^{3}$ versus $22.5 \%$ for V12 Gy $<10 \mathrm{~cm}^{3}$, being significant in multivariate analysis. In contrast, the risk for asymptomatic radionecrosis did not increase with V12 Gy, remaining at 19.1\% for tumors $<10 \mathrm{~cm}^{3}$ and $18.5 \%$ for tumors $>10 \mathrm{~cm}^{3}$, respectively. Few authors have evaluated the predictive value of volume receiving 10 or 12 Gy on the development of radionecrosis after SRS for arteriovenous malformation (AVM) [21,22]. At a median follow-up of 28 months Voges et al [22] reported an actuarial risk of radionecrosis of $38.4 \%$ at 2 years in 62 patients with intraparenchymal lesions, with an incidence of events of $0 \%$ for volumes covered by the $10 \mathrm{~Gy}$ isodose-line $\leq 10 \mathrm{~cm}^{3}$ and $23.7 \%$ for volumes $>10 \mathrm{~cm}^{3}$. Flickinger et al [21] in a series of 307 patients with AVM who received GK SRS at the University of Pittsburgh between 1987 and 1993 observed an incidence of symptomatic radionecrosis of $30.5 \%$ at 7 years. On multivariate analysis, V12 Gy and AVM location were the only independent variable that correlated significantly with brain necrosis.

Although the reported risk of radionecrosis after SRS is variable in the published series depending on different radiosurgical techniques, type of lesion treated, length of follow-up and patient's selection, nevertheless volume receiving 12 Gy may be adopted as the standard method of reporting the dose to the normal brain to estimate the risk of toxicity after SRS. In our department brain metastases with a V12 Gy $>8.5 \mathrm{~cm}^{3}$, which is the midpoint of $3^{\text {rd }}$ quartile corresponding to the risk of developing radionecrosis $>10 \%$ at 1 year, are considered for hypofractionated stereotactic radiotherapy using a dose of 24-27 Gy in 3 fractions rather than single SRS to reduce the risk of treatment-related complications.

In conclusion, SRS represents a feasible option for patients with brain metastases associated with survival benefit, however a significant subset of patients may develop neurological complications. Radionecrosis represents the most important late toxicity after SRS with the brain volumes irradiated at 10 and 12 Gy being the most important independent predictors of brain necrosis. Large lesions at high risk of radiation-induced complications especially when located in/near eloquent areas should be considered for hypofractionated stereotactic radiotherapy.

\section{Acknowledgements}

We are grateful to Mr. Gianluca Marrone and Matteo Luciani for their excellent technical assistance during the study.

\section{Author details}

${ }^{1}$ Department of Radiation Oncology, Sant' Andrea Hospital, University "La Sapienza", Rome, Italy. 'Department of Neurological Sciences, Neuromed Institute, Pozzilli (IS), Italy. ${ }^{3}$ Department of Neuroradiology, Sant' Andrea Hospital, University "La Sapienza", Rome, Italy.

\section{Authors' contributions}

GM conceived the study, participated in its design and coordination, and drafted the manuscript. GL, GT and AR participated in study design, analysis and interpretation of data, and helped to draft the manuscript. EC and MFO performed the statistical analysis and participated in acquisition and analysis of data. AB and RME critically reviewed/revised the article. All authors read and approved the final manuscript. 


\section{Competing interests}

The authors declare that they have no competing interests.

Received: 2 February 2011 Accepted: 15 May 2011

Published: 15 May 2011

\section{References}

1. Pirzkall A, Debus J, Lohr F, Fuss M, Rhein B, Engenhart-Cabillic R, Wannenmacher M: Radiosurgery alone or in combination with wholebrain-radiotherapy for brain metastases. J Clin Oncol 1998, 16:3563-3569.

2. Kondziolka D, Patel A, Lunsford LD, Kassam A, Flickinger JC: Stereotactic radiosurgery plus whole brain radiotherapy versus radiotherapy alone for patients with multiple brain metastases. Int I Radiat Oncol Biol Phys 1999, 45:427-434.

3. Sanghavi SN, Miranpuri SS, Chappell R, Buatti JM, Sneed PK, Suh JH, Regine WF, Weltman E, King VJ, Goetsch SJ, Breneman JC, Sperduto PW, Scott C, Mabanta S, Mehta MP: Radiosurgery for patients with brain metastases: a multi-institutional analysis, stratified by the RTOG recursive partitioning analysis method. Int I Radiat Oncol Biol Phys 2001, 51:426-434.

4. Sneed PK, Suh JH, Goetsch SJ, Sanghavi SN, Chappell R, Buatti JM, Regine WF, Weltman E, King VJ, Breneman JC, Sperduto PW, Mehta MP: A multi-institutional review of radiosurgery alone vs. radiosurgery with whole brain radiotherapy as the initial management of brain metastases. Int J Radiat Oncol Biol Phys 2002, 53:519-526.

5. Andrews DW, Scott CB, Sperduto PW, Flanders AE, Gaspar LE, Schell MC, Werner-Wasik M, Demas W, Ryu J, Bahary JP, Souhami L, Rotman M, Mehta MP, Curran WJ Jr: Whole brain radiation therapy with or without stereotactic radiosurgery boost for patients with one to three brain metastases: phase III results of the RTOG 9508 randomised trial. Lancet 2004, 363:1665-1672.

6. Manon R, O'Neill A, Knisely J, Werner-Wasik M, Lazarus HM, Wagner $\mathrm{H}_{\text {, }}$ Gilbert M, Mehta M: Eastern Cooperative Oncology Group. Phase II trial of radiosurgery for one to three newly diagnosed brain metastases from renal cell carcinoma, melanoma, and sarcoma: an Eastern Cooperative Oncology Group study (E 6397). J Clin Oncol 2005, 23:8870-8876.

7. Aoyama H, Shirato H, Tago M, Nakagawa K, Toyoda T, Hatano K, Kenjyo M, Oya N, Hirota S, Shioura H, Kunieda E, Inomata T, Hayakawa K, Katoh N, Kobashi G: Stereotactic radiosurgery plus whole-brain radiation therapy vs stereotactic radiosurgery alone for treatment of brain metastases: a randomized controlled trial. JAMA 2006, 295:2483-2491.

8. Kocher M, Soffietti R, Abacioglu U, Villà S, Fauchon F, Baumert BG, Fariselli L, Tzuk-Shina T, Kortmann RD, Carrie C, Hassel MB, Kouri M, Valeinis E, van den Berge D, Collette S, Collette L, Mueller RP: Adjuvant whole-brain radiotherapy versus observation after radiosurgery or surgical resection of one to three cerebral metastases: results of the EORTC 22952-26001 study. J Clin Oncol 2011, 29:134-141.

9. Kalkanis SN, Kondziolka D, Gaspar LE, Burri SH, Asher AL, Cobbs CS, Ammirati M, Robinson PD, Andrews DW, Loeffler JS, McDermott M, Mehta MP, Mikkelsen T, Olson JJ, Paleologos NA, Patchell RA, Ryken TC, Linskey ME: The role of surgical resection in the management of newly diagnosed brain metastases: a systematic review and evidence-based clinical practice guideline. J Neurooncol 2010, 96:33-43.

10. Frazier JL, Batra S, Kapor S, Vellimana A, Gandhi R, Carson KA, Shokek O, Lim M, Kleinberg L, Rigamonti D: Stereotactic radiosurgery in the management of brain metastases: an institutional retrospective analysis of survival. Int J Radiat Oncol Biol Phys 2010, 76:1486-1492.

11. Mehta MP, Rozental JM, Levin AB, Mackie TR, Kubsad SS, Gehring MA, Kinsella TJ: Defining the role of radiosurgery in the management of brain metastases. Int I Radiat Oncol Biol Phys 1992, 24:619-625.

12. Joseph J, Adler JR, Cox RS, Hancock SL: Linear accelerator-based stereotaxic radiosurgery for brain metastases:the influence of number of lesions on survival. J Clin Oncol 1996, 14:1085-1092.

13. Lavine SD, Petrovich Z, Cohen-Gadol AA, Masri LS, Morton DL, O'Day SJ, Essner R, Zelman V, Yu C, Luxton G, Apuzzo ML: Gamma knife radiosurgery for metastatic melanoma: an analysis of survival, outcome, and complications. Neurosurgery 1999, 44:59-64.

14. Sneed PK, Lamborn KR, Forstner JM, McDermott MW, Chang S, Park E, Gutin PH, Phillips TL, Wara WM, Larson DA: Radiosurgery for brain metastases: is whole brain radiotherapy necessary? Int I Radiat Oncol Biol Phys 1999, 43:549-558.
15. Majhail NS, Chander S, Mehta VS, Julka PK, Ganesh T, Rath GK: Factors influencing early complications following Gamma Knife radiosurgery. A prospective study. Stereotact Funct Neurosurg 2001, 76:36-46.

16. Varlotto JM, Flickinger JC, Niranjan A, Bhatnagar AK, Kondziolka D, Lunsford LD: Analysis of tumor control and toxicity in patients who have survived at least one year after radiosurgery for brain metastases. Int $J$ Radiat Oncol Biol Phys 2003, 57:452-464.

17. Muacevic A, Kreth FW, Tonn JC, Wowra B: Stereotactic radiosurgery for multiple brain metastases from breast carcinoma. Cancer 2004, 100:1705-1711.

18. Lutterbach J, Cyron D, Henne K, Ostertag CB: Radiosurgery followed by planned observation in patients with one to three brain metastases. Neurosurgery 2003, 52:1066-1073.

19. Kondziolka D, Niranjan A, Flickinger JC, Lunsford LD: Radiosurgery with or without whole-brain radiotherapy for brain metastases: the patients' perspective regarding complications. Am J Clin Oncol 2005, 28:173-179.

20. Williams BJ, Suki D, Fox BD, Pelloski CE, Maldaun MV, Sawaya RE, Lang FF, Rao G: Stereotactic radiosurgery for metastatic brain tumors: a comprehensive review of complications. J Neurosurg 2009, 111:439-448.

21. Flickinger JC, Lunsford LD, Kondziolka D, Maitz AH, Epstein AH, Simons SR, Wu A: Radiosurgery and brain tolerance: an analysis of neurodiagnostic imaging changes after gamma knife radiosurgery for arteriovenous malformations. Int J Radiat Oncol Biol Phys 1992, 23:19-26.

22. Voges J, Treuer H, Sturm V, Büchner C, Lehrke R, Kocher M, Staar S, Kuchta J, Müller RP: Risk analysis of linear accelerator radiosurgery. Int J Radiat Oncol Biol Phys 1996, 36:1055-1063.

23. Shaw E, Scott C, Souhami L, Dinapoli R, Kline R, Loeffler J, Farnan N: Single dose radiosurgical treatment of recurrent previously irradiated primary brain tumors and brain metastases: final report of RTOG protocol 90-05. Int I Radiat Oncol Biol Phys 2000, 47:291-298.

24. Petrovich Z, Yu C, Giannotta SL, O'Day S, Apuzzo ML: Survival and pattern of failure in brain metastasis treated with stereotactic gamma knife radiosurgery. J Neurosurg 2002, 97(5 Suppl):499-506.

25. Korytko T, Radivoyevitch T, Colussi V, Wessels BW, Pillai K, Maciunas RJ, Einstein DB: 12 Gy gamma knife radiosurgical volume is a predictor for radiation necrosis in non-AVM intracranial tumors. Int J Radiat Oncol Biol Phys 2006, 64:419-424.

26. Blonigen BJ, Steinmetz RD, Levin L, Lamba MA, Warnick RE, Breneman JC: Irradiated volume as a predictor of brain radionecrosis after linear accelerator stereotactic radiosurgery. Int I Radiat Oncol Biol Phys 2010, 77:996-1001.

27. Nedzi LA, Kooy H, Alexander E, Gelman RS, Loeffler JS: Variables associated with the development of complications from radiosurgery of intracranial tumors. Int J Radiat Oncol Biol Phys 1991, 21:591-599.

28. Flickinger JC, Kondziolka D, Lunsford LD, Pollock BE, Yamamoto M, Gorman DA, Schomberg PJ, Sneed P, Larson D, Smith V, McDermott MW, Miyawaki L, Chilton J, Morantz RA, Young B, Jokura H, Liscak R: A multiinstitutional analysis of complication outcomes after arteriovenous malformation radiosurgery. Int I RadiatOncol Biol Phys 1999, 44:67-74.

29. Minniti G, Salvati M, Muni R, Lanzetta G, Osti MF, Clarke E, Costa A, Bozzao A, Trasimeni G, Enrici RM: Stereotactic radiosurgery plus wholebrain radiotherapy for treatment of multiple metastases from non-small cell lung cancer. Anticancer Res 2010, 30:3055-3061.

30. Collins SP, Coppa ND, Zhang Y, Collins BT, McRae DA, Jean WC: CyberKnife radiosurgery in the treatment of complex skull base tumors: analysis of treatment planning parameters. Radiat Oncol 2006, 1:46.

31. Muacevic A, Kreth FW, Horstmann GA, Schmid-Elsaesser R, Wowra B, Steiger HJ, Reulen HJ: Surgery and radiotherapy compared with gamma knife radiosurgery in the treatment of solitary cerebral metastases of small diameter. J Neurosurg 1999, 91:35-43.

32. Shinoura N, Yamada R, Okamoto K, Nakamura O, Shitara N: Local recurrence of metastatic brain tumor after stereotactic radiosurgery or surgery plus radiation. J Neurooncol 2002, 60:71-77.

33. Rades D, Bohlen G, Pluemer A, Veninga T, Hanssens P, Dunst J, Schild SE: Stereotactic radiosurgery alone versus resection plus whole-brain radiotherapy for 1 or 2 brain metastases in recursive partitioning analysis class 1 and 2 patients. Cancer 2007, 109:2515-2521.

34. Muacevic A, Wowra B, Siefert A, Tonn JC, Steiger HJ, Kreth FW: Microsurgery plus whole brain irradiation versus Gamma Knife surgery alone for treatment of single metastases to the brain: a randomized controlled multicentre phase III trial. J Neurooncol 2008, 87:299-307. 
35. Rades D, Kueter JD, Pluemer A, Veninga T, Schild SE: A matched-pair analysis comparing whole-brain radiotherapy plus stereotactic radiosurgery versus surgery plus whole-brain radiotherapy and a boost to the metastatic site for one or two brain metastases. Int I Radiat Oncol Biol Phys 2009, 73:1077-1081.

36. Firlik KS, Kondziolka D, Flickinger JC, Lunsford LD: Stereotactic radiosurgery for brain metastases from breast cancer. Ann Surg Oncol 2000, 7:333-338.

37. Gianni L, Eiermann W, Semiglazov V, Manikhas A, Lluch A, Tjulandin S, Zambetti M, Vazquez F, Byakhow M, Lichinitser M, Climent MA, Ciruelos E, Ojeda B, Mansutti M, Bozhok A, Baronio R, Feyereislova A, Barton C, Valagussa P, Baselga J: Neoadjuvant chemotherapy with trastuzumab followed by adjuvant trastuzumab versus neoadjuvant chemotherapy alone, in patients with HER2-positive locally advanced breast cancer (the $\mathrm{NOAH}$ trial): a randomised controlled superiority trial with a parallel HER2-negative cohort. Lancet 2010, 375:377-384.

38. Herbst RS, Sun Y, Eberhardt WE, Germonpré P, Saijo N, Zhou C, Wang J, Li L, Kabbinavar F, Ichinose Y, Qin S, Zhang L, Biesma B, Heymach JV, Langmuir P, Kennedy SJ, Tada H, Johnson BE: Vandetanib plus docetaxel versus docetaxel as second-line treatment for patients with advanced non-small-cell lung cancer (ZODIAC): a double-blind, randomised, phase 3 trial. Lancet Oncol 2010, 11:619-626.

39. Miles DW, Chan A, Dirix LY, Cortés J, Pivot X, Tomczak P, Delozier T, Soh JH, Provencher L, Puglisi F, Harbeck N, Steger GG, Schneeweiss A, Wardley AM, Chlistalla A, Romieu G: Phase III study of bevacizumab plus docetaxel compared with placebo plu docetaxel for the first-line treatment of human epidermal growth factor receptor 2-negative metastatic breast cancer. J Clin Oncol 2010, 28:3239-3247.

40. Reck M, von Pawel J, Zatloukal P, Ramlau R, Gorbounova V, Hirsh V, Leighl N, Mezger J, Archer V, Moore N, Manegold C, BO17704 Study Group: Overall survival with cisplatin-gemcitabine and bevacizumab or placebo as first-line therapy for nonsquamous non-small-cell lung cancer: results from a randomised phase III trial(AVAiL). Ann Oncol 1770, 21:1804-1809.

41. Takeda $K$, Hida T, Sato T, Ando M, Seto T, Satouchi M, Ichinose $Y$, Katakami N, Yamamoto N, Kudoh S, Sasaki J, Matsui K, Takayama K, Kashii T, Iwamoto Y, Sawa T, Okamoto I, Kurata T, Nakagawa K, Fukuoka M: Randomized phase III trial of platinum-doublet chemotherapy followed by gefitinib compared with continued platinum-doublet chemotherapy in Japanese patients with advanced non-small-cell lung cancer: results of a west Japan thoracic oncology group trial (WJTOG0203). J Clin Oncol 2010, 28:753-760.

42. Noel G, Bollet MA, Noel S, Feuvret L, Boisserie G, Tep B, Delattre JY, Baillet F, Ambroise Valery C, Cornu P, Mazeron JJ: Linac stereotactic radiosurgery: an effective and safe treatment for elderly patients with brain metastases. Int J Radiat Oncol Biol Phys 2005, 63:1555-1561.

43. Kim SH, Weil RJ, Chao ST, Toms SA, Angelov L, Vogelbaum MA, Suh JH, Barnett GH: Stereotactic radiosurgical treatment of brain metastases in older patients. Cancer 2008, 113:834-840.

doi:10.1186/1748-717X-6-48

Cite this article as: Minniti et al: Stereotactic radiosurgery for brain metastases: analysis of outcome and risk of brain radionecrosis. Radiation Oncology 2011 6:48.

\section{Submit your next manuscript to BioMed Central and take full advantage of:}

- Convenient online submission

- Thorough peer review

- No space constraints or color figure charges

- Immediate publication on acceptance

- Inclusion in PubMed, CAS, Scopus and Google Scholar

- Research which is freely available for redistribution

Submit your manuscript at www.biomedcentral.com/submit
CioMed Central 